\title{
JH

\section{Social media and the spread of COVID-19 conspiracy theories in Nigeria}

\author{
Sarah Gambo ${ }^{*}$, Woyopwa Shem ${ }^{1}$
}

\begin{abstract}
Background: Amidst the recent outbreak of the Covid-19 pandemic, there seems to be an avalanche of conspiracy theories that abound on social media platforms, and this subject attracted a lot of research interest. This study aimed to examine the "social media and the spread Covid-19 conspiracy theories in Nigeria" in light of the above.

Methods: The study adopted a qualitative design in order to explore the subject matter thoroughly. Thirty-five participants were conveniently sampled, and interviews were conducted to retrieved data from the participants.

Results: Findings of this study revealed that there is a prevalence of conspiracy theories that have saturated social media ever since the outbreak of the Covid-19 pandemic. It was also found that ignorance, religious fanaticism, lack of censorship, and insufficient counter information on social media platforms are some of the possible factors that aided the spread of Covid-19 conspiracy theories among Nigerian social media users.
\end{abstract}

Conclusion: This study recommends, among other things, that there is a swift need to curtail the spread of conspiracy theories through consistent dissemination of counter-information by both individuals and agencies like the National Orientation Agency (NOA) and the Nigerian Centre for Disease and Control (NCDC).

Keywords: Social Media, Conspiracy Theories, COVID-19, Pandemic, Nigeria

\section{Background}

'If you want the truth to go round the world, you must hire an express train to pull it; but if you want a lie to go round the world, it will fly; it is as light as a feather, and a breath will carry it. It is well said in the old proverb, "a lie will go round the world while the truth is pulling its boots on" [1]. From the above assertion, it is apposite to infer that amidst the present advancement in the area of information communication technology, social media serve as that "breath" that carries lies across the globe. In other words, evidence from extant studies revealed that social media serves as an aircraft that carries lies in the form of conspiracy theories and misinformation worldwide. Varis P. [2] substantiates that social media platform play an enormous role in spreading conspiracy theories and the exposure they get. Faddoul M, et al. [3] corroborate that conspiracy theories have continued to flourish on social media, raising fear and anxiety that such content is fueling the spread of disinformation. As such, Rampersad G, et al. [4] affirm that social media serve as a medium for swift dissemination of

*Correspondence: gamssarah@gmail.com

${ }^{1}$ Faculty of Communication and Media Studies, Taraba State University, Taraba State, Nigeria.

Full list of author information is available at the end of the article misinformation and fake news. Since the beginning of the novel coronavirus disease (Covid-19) epidemic, which started in December 2019 in Wuhan, the capital of Hubei, China [5], misinformation has been spreading uninhibited over traditional and social media at a rapid pace [6]. According to Bamidele M. [7], the world is currently under the siege of the Coronavirus (COVID-19), a deadly disease that the World Health Organization (WHO) has declared a pandemic.

Bamidele M. [7] added that the number of confirmed cases of infections and deaths has left many in panic and served as the catalyst to breed various forms of conspiracy theories and myths. Ghalib and Take [8] corroborates that the Covid-19 outbreak has sparked what the World Health Organization (WHO) called "infordemic" an overwhelming amount of information on social media and website". Apuke and Omar [9] expressed worry over this overwhelming amount of information on social media when they postulated that social misinformation had stimulated the public regarding Covid-19.

According to extant studies [3,5], there is an avalanche of rumors and conspiracy theories circulating the internet. In fact, it has become tricky to differentiate between fake news from factual reportage [10]. In light of the above, Lampos et al. [12] argued that as the cases of Covid-19 worldwide increased, the spread of misinformation concerning the virus increased. 
Social media platforms such as YouTube and Twitter provide direct access to an unprecedented amount of content and may amplify rumors and questionable information [13]. Therefore, suffice it to infer that individual online, knowingly, and unknowingly, spread information at an alarming rate, which could be dangerous or misleading [14]. Simply put, social media has become a channel for rapidly increasing rumors and deliberate misinformation, and many are deploying sites such as Facebook, Twitter, YouTube, and WhatsApp to create a state of panic and confusion, especially amidst the recent outbreak of the coronavirus pandemic. Pennycook G, et al. [15] affirm that misinformation can amplify humanity's greatest challenges. They further argued that a significant topical example of this is the Covid-19 pandemic, which has nurtured an avalanche of fabrications even as truth has increasingly become a matter of life-and-death. A study conducted by Gallup/Knight Foundation [16] revealed that overall, Americans believe $39.0 \%$ of the news they see on television, read in newspapers, or hear on the radio is misinformation. Furthermore, [16] findings revealed that Americans estimate that nearly two-thirds of the news they see on social media is misinformation. From the foregoing, it is apt to investigate why social media platforms serve as carriers of conspiracy theories and misinformation, which eventually result in panic among the public.

\section{Purpose of the Study}

The core purpose of this current study is to investigate why and how social media platforms foster conspiracy theories, especially amidst the Covid-19 outbreak. However, the specific objectives are:

1.To find out whether there are pervasiveness conspiracy theories on Covid-19 in social media;

2.To ascertain possible factors responsible for the spread of conspiracy theories on Covid-19 in social media platforms;

3.To suggest possible measures on how to curb the spread of conspiracy theories on social media platforms.

\section{Literature Review}

There are extant studies on social media, conspiracy theories, and Covid-19. Hence, the researchers deem it is apt to review this literature for clarity on the subject matter. The literature is reviewed in the following sub-themes: social media, conspiracy theories, and Covid-19: a conceptual review.

\section{Social Media, Conspiracy Theories and Covid-19: A Conceptual Review}

1. Social media: Despite the plethora of extant studies on social media, it is obvious that the concept of "social media" has no universally accepted definition because; the term social media is used differently by people in various contexts that are in tandem with their perspectives [17]. For instance, to Kaplan and Haenlein [18], social media is "a group of Internet-based applications that are built on the ideological and technological foundations of Web 2.0 and that allow the creation and exchange of User Generated Content" while Baltatzis P. [19] defined social media as an "online platforms that promote participation, openness, conversation, and connectedness".

Buettner R. [20] opined that social media is a computermediated tool that has the potency to its users to generate and share information, career interests, etc. Baltatzis P. [19] defined social media as a medium where people communicate, utilizing online platforms while they are connected to the Internet. From the above definitions, it could be deduced that social media platforms are actually internet-based applications that allow users to create, share and disseminate information freely. Suffice it to say that the social media platforms allow its users both old and young, literate and illiterate, propagandist, and counter spin to share and disseminate information. Brindha $\mathrm{MD}$, et al. [14] claim surface in the form of conspiracy theories. Based on the above definitions, it is apposite to infer that social media has various features that may contribute to making the medium a carrier of conspiracy theories.

2. Conspiracy theory: The words rumor, and conspiracy theories are closely tied [22]. Runnels [22] further argued that rumors serve as one catalyst that fosters the spread of conspiracy theories. In his words, he captured it this: Rumours provide a mechanism by which a conspiracy theory spreads through a population. For example, various conspiracy theories on the Internet attempt to identify the "real" culprits behind 9/11, but, in this author's opinion, those theories are typically summed up and spread by the rumor that $9 / 11$ was an inside job (p10). According to Cass and Adrian [23], a conspiracy theory is "an effort to explain some event or practice by reference to the machinations of powerful people, who have also managed to conceal their role". Bale JM. [24] defines conspiracy theory as the certainty, assurance, or "certainty that a group of actors meets in secret agreement with the purpose of attaining some selfish but malicious goal". Oxford English Dictionary defines conspiracy theory as "the theory that an event or phenomenon occurs as a result of a conspiracy between interested parties". "Conspiracy theories" refers to any effort to explain the rationale behind the occurrence of social or political circumstances with claims of secret plots by either two or more powerful actors [25].

Suffice it to say that a conspiracy theory is an explanation for an event or occurrence based on a malicious plot with the sole aim of achieving a specific goal. Prooijen and Vogt [26] postulated that "conspiracy theories make an assumption of how people, objects, or events are causally interconnected". This implies that initiators of conspiracy theories give convincing yet pseudo reasons for people to believe their explanation of events or occurrences. Notwithstanding, Lewandowsky [27] argued that "conspiracy theories are not always the result of genuinely held false beliefs". Lewandowsky [27] noted that conspiracy theories could be intentionally constructed or amplified for strategic, political reasons.

3. Covid-19: "In December 2019, cluster phenomena cases appeared in China, and its shape was like Crown and crown mean Corona, so its name was given Corona Virus" [28]. Coronaviruses are a family of viruses that cause respiratory symptoms [29]. The most recent outbreak of the virus in late December 2019 is named Covid-19. (Khan, 2020, p.2) opined that the symptoms include cough, pneumonia, fever, shortness of breathing, and throat sore.

\section{Theoretical Underpinning}

The Uses and Gratification Theory (UGT) was found suitable for this research study. The Uses and Gratification Theory was developed by Katz, Blumler, and Gurevitch in 1974 [29]. The 
Uses and gratifications theory basically focused on how and why the audience uses the media (Klapper, 1963). Commenting on the uses and gratification theory, McQuail [30] stated that the central question posed by the uses and gratification theory is "why do people use media, and what do they use them for?" Simply put, the uses and gratification theory is built on the premise that people use the media not just for using sake but as a result of the satisfaction they obtained from the media [31]

In his view, Mohammed A. [17] opined that the audiences select the medium and even what content is most suitable to their personal desires. When the uses and gratification theory was propounded, it was used to study audiences for traditional media [31], but today, it is relevant in the study of issues relating to social media forms. The veracity of the above is linked to the fact that social media users these days also select which platform gratifies them. The uses and gratifications theory finds strength in describing how media audiences seek information and use it to satisfy their personal goals [17]. In light of the above, Baran and Davis [32] state that the uses and gratification theory acknowledged the intellectuality of the audience and their ability to consume only what is needful for them. From the above, it is obvious that there is a nexus between the uses and gratifications theory and this current research study despite the existing differences between new media and traditional media. This theory finds relevance in this current study because of its interactive processes. This can be further buttressed that the new wave in research on communication and media studies focuses on how audiences interact with and are influenced by the type of media they choose. Suffice it to say that the applicability of the uses and gratification to this current becomes palpable because most conspirators or initiators of conspiracy theories or misinformation used the social media platforms to satisfy their gratification. Furthermore, the conspiracy theories tend to spread like wildfire due to the gratification that other users may find in sharing them with family and friends.

\section{Methods}

A qualitative research design was used in other gather data for this research study. Purposely, the phenomenological method was used to understand how participants make meaning of the phenomenon studied. Brindha MD, et al. [14] state that phenomenology effectively studies a small number of subjects which is why thirty-five participants were selected conveniently and interviewed. The rationale behind the use of interview is simply because interview has the potency to unravel or bring out hidden feelings, attitudes, and beliefs that an interviewee is unaware of [33]. Further to the above reason, the researchers observed that limited extant related studies adopted this method to explore the theme under investigation, which is "social media and the spread of conspiracy theories on Covid-19 pandemic in Nigeria".

\section{Participant and Sampling}

The participants of this study were conveniently drawn from Yola, Adamawa State, Nigeria. Yola is the State Capital (headquarters) of Adamawa State, Nigeria. The rationale behind choosing participants from the above location is due to convenience and the location's proximity to the researchers. As discussed earlier, the thirty-five participants conveniently selected and deemed apt for this study volunteered to participate in this research study. It is also pertinent to note that all the selected participants were active social media users. Ten of them were academicians specializing in communication and media studies, which put them in a vantage position to contribute meaningfully to this research study. Out of the 35 participants $(n=17)$ were male and $(n=18)$ were female.

In terms of educational qualification $(n=22)$, participants had at least a high school certificate as their highest educational qualification while $(n=12)$ had a college degree as their highest qualification ( 8 had master's degree while 6 bachelor's degrees). It is apposite to note that the entire participants were coded as Participant 1, 2 3....and so on. The above is in tandem with the conventional practice of qualitative research which most often than not, researchers assured the participants of anonymity with the sole aim of encouraging them to conveniently unravel information that would be of enormous significance in achieving the purpose of the study.

\section{Data Collection Procedure}

The researchers adopted face-face semi-structured interviews to retrieved data for this study. The interviews lasted for approximately one month (four weeks). Three communication research experts scrutinized the interview question guide, and a pre-test was conducted using 10 participants who were not part of the sampled respondent. The interviews were conducted with the help of two research assistants that aided in recording the interviews on tape as the researchers conduct the interviews. It is worthy to note that each interview session lasted between thirty minutes to one hour, and the recorded interviews were later transcribed verbatim.

\section{Data Analysis}

In order to analyze the data retrieved for this study, the researchers, with the help of research assistants, meticulously transcribed all recorded interviews, after which the data were interpreted and discussed thematically with the help of extant related studies. Four sub-themes were identified, interpreted, and discussed in tandem with the objective of this study. These sub-themes include the presence of conspiracy theories on Covid-19 on social media platforms, possible factors that foster the spread of conspiracy theories on covid-19, and possible measures on how to curb the spread of conspiracy theories on social media platforms.

\section{Results and Discussion}

This section is organized and segmented into three sub-themes to interpret and explicate the study results thoroughly. The three sub-themes were actually coined out of the objectives of this current study. The sub-themes are:

1. Presence of Covid-19 conspiracy theories on social media platforms.

2. Factors responsible for the spread of Covid-19 conspiracy theories on social media.

3. Possible measures on how to curb the spread of conspiracy theories on social media platforms.

The first sub-theme seeks to ascertain whether conspiracy theories on Covid-19 abound on social media platforms, as some of the reviewed literature claimed. In contrast, the second sub-theme discussed some of the possible factors responsible 
for spreading Covid-19 conspiracy theories on social media platforms. The third sub-theme sought to proffer a solution on how to curb the spread of Covid-19 conspiracy theories among Nigerian social media users.

Table 1: Participants' responses

\begin{tabular}{|l|l|l|}
\hline S/N & Statements & Response \\
\hline 1 & $\begin{array}{l}\text { Was bioengineered in a lab } \\
\text { in Wuhan, China }\end{array}$ & $\begin{array}{l}35 \text { participants said Yes } \\
\text { while 0 said No }\end{array}$ \\
\hline 2 & $\begin{array}{l}5 \text { G technology } \\
\text { causes coronavirus }\end{array}$ & $\begin{array}{l}28 \text { participants said Yes } \\
\text { while seven said No }\end{array}$ \\
\hline 3 & $\begin{array}{l}\text { Nostradamus predict } \\
\text { coronavirus }\end{array}$ & $\begin{array}{l}19 \text { participants said Yes } \\
\text { while 16 said No }\end{array}$ \\
\hline 4 & $\begin{array}{l}\text { Coronavirus is a death } \\
\text { sentence }\end{array}$ & $\begin{array}{l}18 \text { participants said Yes } \\
\text { while 17 said No }\end{array}$ \\
\hline 5 & $\begin{array}{l}\text { Coronavirus is an airborne } \\
\text { HIV }\end{array}$ & $\begin{array}{l}21 \text { participants said Yes } \\
\text { while 14 said No }\end{array}$ \\
\hline 6. & $\begin{array}{l}\text { Bill Gates orchestrates } \\
\text { coronavirus }\end{array}$ & $\begin{array}{l}19 \text { participants said Yes } \\
\text { while 16 said No }\end{array}$ \\
\hline 7. & $\begin{array}{l}\text { Coronavirus is spread via } \\
\text { corona beers and cured with } \\
\text { garlic water }\end{array}$ & $\begin{array}{l}\text { 22 participants said Yes } \\
\text { while 13 said No }\end{array}$ \\
\hline 8. & $\begin{array}{l}\text { Coronavirus is here to teach } \\
\text { us a lesson }\end{array}$ & $\begin{array}{l}\text { 23 participants said Yes } \\
\text { while 12 said No }\end{array}$ \\
\hline
\end{tabular}

Source: Authors Interview, 2020

Presence of Covid-19 Conspiracy theories on social media platforms

Additionally, it was found that the majority of the participants did not just concur that conspiracy theories exist on social media platforms but that there is a high degree of these conspiracy theories flooding the social media platforms. One of the interviewed participants claimed that:

There is much information on social media platforms since the outbreak of the coronavirus. Even though some of this information may be factual yet I strongly believe that the majority of them are pseudo, misinforming, and sound illogical. In fact, I have seen and read almost all the conspiracy theories you outlined earlier either through my Facebook account or WhatsApp. [Participant 12].

Substantiating the overhead view, another interviewee affirmed that: social media, especially Facebook and WhatsApp, are saturated with many conspiracy theories on the new coronavirus; in fact, these theories are so many that you do not know which one to believe. [Participant 7].

Similarly, another participant stated that: Asking one whether conspiracy theories abound on social media platforms seems to be a waste of time because we all know that social media platforms accommodate conspiracy theories, especially amidst the outbreak of Covid-19. [Participant 5].

Based on the above findings, it is palpable to infer that there is certainly an overwhelming presence of conspiracy theories on different social media platforms. Therefore, it is apposite to infer that the above findings conceded with studies that unraveled that conspiracy theories exist on social media platforms. For instance, Ghada and Takshe [8] claimed that the Covid-19 outbreak has sparked what the World Health
Organization (WHO) called "infordemic" an overwhelming amount of information on social media and website".

Similarly, a study conducted by Dopoux P, et al. [34] revealed that: Within weeks of the emergence of the novel coronavirus COVID-19 in China, misleading rumors and conspiracy theories about the origin circulated the globe paired with fearmongering, racism, and mass purchase of face masks, all closely linked to the new "Infomedia" ecosystems of the $21 \mathrm{st}$ century marked by social media (p1).

The above implies that the social media platforms are part of the factors that give prominence and acceptance to Covid-19 Conspiracy theories.

Factors responsible for the spread of conspiracy theories on social media

Here, the interviewed participants were asked to identify some possible factors that tend to promote the spread of covid-19 conspiracy theories on social media platforms in Nigeria. The majority of the participant pinpointed ignorance and religious fanaticism as the core factors that aided the spread of conspiracy theories related to Covid-19 among Nigerian social media users. The above finding conceded with some media reportage. For instance, "The Guardian" reported on Monday, being the $18^{\text {th }}$ of May 2020, that a religious-based television channel was sanction for airing "potentially harmful statements" about the Covid-19 pandemic, including baseless conspiracy that the virus is linked to the rollout of $5 \mathrm{G}$ phone networks.

In respect of the above view, one of the interviewed participants states that: Religious fanaticism is one of the factors that may perhaps promote the spread of Covid-19 conspiracy theories on social media platforms in Nigeria. The fact is that Nigerians are religious people; hence they tend to believe their religious leaders more than any other authority. Furthermore, it is quite unfortunate that some of the religious leaders from the two dominant religions in Nigeria still hold on to specific conspiracy theories. Some of them do not even believe that the virus exists. [Participant 10].

Supporting the above view, another participant said:

Ignorance and religious fanaticism are two significant promoters of conspiracy theories among Nigerian social media users. Although Nigerians can be obsessive with their religious beliefs, they also have a poor reading culture. Albeit this claim could be argued but with my experience as an academician, I can boldly say that Nigerians have a poor reading culture. Therefore, I am pretty sure that the majority of Nigerians may not take time to read about the coronavirus from reliable sources (websites) such as World Health Organizations or Nigerian Centre for Disease and Control but will prefer to rely upon and share the information they got from social media platforms of which most of this information on social media are pseudo and unreliable.[Participant 15].

The above participant further notes that because Nigerians have poor reading culture hence, they could easily be convinced by their religious leaders, who in most cases are just like their demigod. The above scenario may result in some superstitious beliefs. For instance, at the early stage of the Covid-19 outbreak, there are superstitious believes trending among social media users in Nigeria that the virus is a sort of punishment from God and that the virus has been prophesied long ago. Other factors responsible for the spread of conspiracy theories 
that were pinpointed by other interviewed participants include lack of censorship and insufficient counter information by relevant agencies.

One of the participants claimed that: Lack of sufficient counter information is one of the factors that may be responsible for promoting conspiracy theories among Nigerian social media users. In fact, one can boldly say that agencies like National Orientation Agencies and Nigerian Centre for Disease and Control are not disseminating adequate information that would counteract the Covid-19 conspiracy theories that saturate social media. Moreover, I think that is one of the reasons or catalysts responsible for the spread of misinformation on coronavirus among Nigerians. [Participant 35].

Another participant also notes that:

I must confess that Nigerians still lack adequate awareness of Covid-19 because most of the so-called awareness campaigns on the Covid-19 pandemic are always urban-oriented. Moreover, we all know that about $70.0 \%$ of Nigerians reside in rural areas, and it is important to state that these ruralites also make use of social media to disseminate information concerning the virus. All I am trying to say is that if the ruralite is not informed and enlightened, then they may likely share or believe any information they got from social media platforms.

\section{[Participant 27].}

The implication of the above is the need for public enlightenment in every nook and cranny of Nigeria. This would help to counteract any misinformation about Corona on both social media and conventional media.

Possible measures on how to curb the spread of conspiracy theories on social media platforms.

Here, emphasis is given to those participants who have a background in media and communication studies. The participants were asked to pinpoint some of the possible ways to effectively curb the spread of conspiracy theories on social media platforms in Nigeria. It was found that the majority of the participants were of the opinion that the consistent dissemination of counter-information, censorship of social media platforms, educating citizen journalists, and public enlightenment are some of the possible ways to curb the spread of conspiracy theory on social media platforms in Nigeria.

One of the participants suggested thus:

I think one of the possible ways to check the spread of conspiracy theories in an environment like Nigeria is by consistently enlightening the public with sufficient information that could counter the conspiracy theories. This is because, from comments of some of my Facebook friends, I figured out that most of the social media users in Nigeria lack sufficient counter information on some of these conspiracy theories, and that is why they tend to like and share conspiracy theories on social media platforms. [Participant 18].

Another participant suggested that: The major problem with social media usage in Nigeria is lack of censorship. Even though censorship may hamper the citizens' fundamental human rights, but it is also important to note that our freedom should have limits, especially in a situation where freedom is likely becoming inimical to the growing society. The early a law is enacted on social media using the better for all of us. [Participants 26].
Another participant added that to effectively combat the spread of Covid-19 conspiracy theories on social media platforms in Nigeria, the conventional media has a role to play through consistent campaigns on radio and television to counteract conspiracy theories on different social media platforms. Based on the above, this present study has shown that conspiracy theories can effectively be managed or curbed through censorship, consistent dissemination of information that debunks or counter the conspiracy theories, and public enlightenment.

\section{Conclusion}

From the findings of this study, it is evident that ever since the outbreak of the Covid-19 pandemic, there is an overwhelming presence of conspiracy theories on social media platforms in Nigeria and the world at large. It is also pertinent to note that ignorance, religious fanaticism, lack of censorship, and insufficient counter information on social media platforms are some of the possible factors that aided the spread of Covid-19 conspiracy theories among social media users in Nigeria. In light of the above, this study recommends, among other things, that there is a swift need to curtail the spread of these conspiracy theories through consistent dissemination of counter-information by individuals and relevant agencies such as the Nigerian Centre for Disease and Control and National Orientation Agency. Furthermore, there is also the need to censor social media platforms by checkmating what should be disseminated by users and what should not be disseminated. In other words, both social media companies and individuals are responsible for ensuring the fight against misinformation concerning conspiracy theories online.

\section{Abbreviation}

NOA: National Orientation Agency; NCDC: Nigerian Centre for Disease and Control; COVID-19: Coronavirus Disease-19; WHO: World Health Organization

\section{Declaration}

acknowledgment

The authors would like to express gratitude to participants who helped in filling the google form

Funding

The authors received no financial support for their research, authorship, and/or publication of this article.

Availability of data and materials

Data will be available by emailing shem.woyopwa@yahoo.com

\section{Authors' contributions}

Sarah Gambo (SG) and Shem Woyopwa (SW) were the study designers, coordinating all aspects of the research and drafting and reviewing the article. All authors (Sarah Gambo and Woyopwa Shem) have read, contributed to amending, and collectively approved the final version of the manuscript.

Ethics approval and consent to participate

We conducted the research following the Declaration of Helsinki. On the date of 12th June 2020, (meeting number 2020/01/08) Department of Mass Communication Scientific Research and Publication Ethics Committee has granted Sarah Gambo and Woyopwa Shem the ethical approval to conduct a research on "Social Media and the Spread of Covid-19 Conspiracy Theories in Nigeria." This decision has been taken by the Chairman of the Ethics Committee, Taraba State University, Jalingo, Nigeria, Dr. Chiakaan Jacob Gbaden. (Reference No.: FCMS/RCH/2020-0345). The participants were assured of confidentiality as stated in the google form. 
Consent for publication

Not applicable

\section{Competing interest}

The authors declare that they have no competing interest.

Open Access

This article is distributed under the terms of the Creative Commons $\begin{array}{llll}\text { Attribution } & 4.0 & \text { International License }\end{array}$ (http://creativecommons.org/licenses/by/4.0/), which permits unrestricted use, distribution, and reproduction in any medium, provided you give appropriate credit to the original author(s) and the source, provide a link to the Creative Commons license, and indicate if changes were made. The Creative Commons Public Domain Dedication waiver (http://creativecommons.org/publicdomain/zero/1.0/) applies to the data made available in this article, unless otherwise stated.

Author details

${ }^{1}$ Faculty of Communication and Media Studies, Taraba State University, Taraba State, Nigeria.

Article Info

Received: 14 July 2021

Accepted: 10 August 2021

Published: 20 August 2021

\section{References}

1. Spurgeon H. (1859) quoted in Ratcliffe S (2000) Concise Oxford Dictionary of Thematic Quotations, USA: Oxford University Press.

2. Varis P. Conspiracy theorising online. Diggit Magazine. 2018. Available from: https://www.diggitmagazine.com/articles/conspiracy-theorisingonline

3. Faddoul M, Chaslot G, Farid H. A longitudinal analysis of YouTube's promotion of conspiracy theories. arXiv Preprint arXiv:2003.03318, (2020). Retrieved from https://arxiv.org/pdf/2003.03319

4. Rampersad G, Althiyabi T, Warner-Søderholm G, Bertsch A, Sawe E, Lee DD, et al. Birds of a Feather: Homophily in Social Networks. Computers in Human Behavior. 2019;9(1):1-9. doi: 10.1126/science.aao2998.

5. Mejova Y, Kalimeri K. Advertisers jump on coronavirus bandwagon: Politics, news, and business. arXiv preprint arXiv:2003.00923, (2020). Retrieve from https://arxiv.org/pdf/2003.00923

6. Kouzy R, Abi Jaoude J, Kraitem A, El Alam MB, Karam B, Adib E, et al. Coronavirus Goes Viral: Quantifying the COVID-19 Misinformation Epidemic on Twitter. Cureus. 2020 Mar 13;12(3):e7255. doi: 10.7759/cureus.

7. Bamidele M. 4 conspiracy theories on Corona Virus. 22 March 2020. Available from: https://guardian.ng/life/conspiracy-theorieson-coronavirus/amp/

8. Ghada MA, Takshe AA. COVID-19: Virus or Viral Conspiracy Theories?AJBSR2020;8(2). Doi:10.34297/AJBSR.2020.08.001252

9. Apuke OD, Omar B. Modelling the antecedent factors that affect online fake news sharing on COVID-19: the moderating role of fake news knowledge. Health Education Research 2020; 35(5): 490-503. https://doi.org/10.1093/her/cyaa030

10. Zhou W, Wang A, Xia F, Xiao Y, Tang S. Effects of media reporting on mitigating spread of COVID-19 in the early phase of the outbreak. Mathematical Biosciences and Engineering2020;17(3):2693-2707. https://doi.org/10.3934/mbe.2020147

11. Lampos V, Moura S, Yom-Tov E, Cox IJ, McKendry R. Tracking COVID-19 using online search. npj Digit. Med.2021; 4: 17. https://doi.org/10.1038/s41746-021-00384-w

12. Zulkifli NA, Sivapatham S, Guan NC. Brief psychotic disorder in relation to coronavirus COVID-19 outbreaks: a case report. Malay J Psychiatry2020; 29:1-6
13. Cinelli M, Quattrociocchi W, Galeazzi , Valensise C, Brugnoli E, et al. The COVID-19 social media infodemic. Sci Rep2020; 10 16598. https://doi.org/10.1038/s41598-020-73510-5

14. Brindha MD, Jayaseelan R, Kadeswara S. Social media reigned by information or misinformation about COVID-19: a phenomenological study. SSRN Electronic Journal 2020; 09(03):585-602. DOI: 10.2139/ssrn.3596058

15. Pennycook G, McPhetres J, Zhang Y, Lu JG, Rand DG. Fighting COVID-19 misinformation on social media: experimental evidence for a scalable accuracy-nudge intervention. Psychol Sci. 2020 Jul;31(7):770-780. doi: 10.1177/0956797620939054

16. Knight Foundation (2018) Americans' Views: Trust media and democracy. USA: Gallup/Knight Foundation. Available from: https://knightfoundation.org/reports/american-views-trust-mediaand-democracy/

17. Mohammed A. Social media use among Nigerian students abroad. Submitted to the institute of graduate studies and research in partial fulfillment of the requirements for the degree of Master of Arts in communication and Media Studies Eastern Mediterranean University, Gazimağusa, North Cyprus, 2015. http://hdl.handle.net/11129/2733

18. Kaplan AM, Haenlein M. Users of the world unite! The challenges and opportunities of social media. Business Horizon 2010; 53(1): 59-68. https://doi.org/10.1016/j.bushor.2009.09.003

19. Baltatzis P. Is blogging innovation journalism? Innovation Journalism2006;3(4).Available from: http://www.ufrgs.br/limc/participativo/pdf/blogging.pdf

20. Buettner R. Personality as a predictor of business social media usage: an empirical investigation of Xing usage patterns 2016 PACIS $2016 \quad$ Proceedings. https://aisel.aisnet.org/pacis2016/163

21. Cox JT, Rethman KM. Setting expectations: Social networking at work. Ohio Lawyer, 17-19. 2011.

22. Runnels RC. Iran's social media message and its connection to conspiracy theories. NPS Archive: Calhoun 2015. Available from https://calhoun.nps.edu/handle/10945/48134

23. Cass RS, Adrian V. Conspiracy Theories: Causes and Cures. Journal of Political Philosophy 2009:17(2):4

24. Bale JM. Political paranoia v. political realism: on distinguishing between bogus conspiracy theories and genuine conspiratorial politics. Patterns of Prejudice2020; 41(1): 45-60. https://doi.org/10.1080/00313220601118751

25. Byford J. Conspiracy theories: A critical introduction. 2011 UK: Palgrave Macmillan.

26. van Prooijen JW, van Vugt M. Conspiracy theories: evolved functions and psychological mechanisms. Perspect Psychol Sci. 2018 Nov;13(6):770-788. doi: 10.1177/1745691618774270.

27. Lewandowsky S. The "post-truth" world, misinformation, and information literacy: a perspective from cognitive science. In S. Goldstein (Ed.), Informed Societies-Why Information Literacy Matters for Citizenship, Participation, and Democracy. Facet. 2020.

28. Cinelli M, Quattrociocchi W, Galeazzi A, Valensise CM, Brugnoli E. The COVID-19 social media Infodemic. arXiv preprint arXiv:2003.05004, 2020. Avilable from: https://arxiv.org/pdf/2003.05004.pdf?fbclid=IwAR08xVUpifbp5Q KhwP3FPqu7J6oA swtPoLJiG6pIgumFfQfnVRmI5Z8Sho in May 2020

29. Wimmer RD, Dominick JR. Mass media research: an introduction. 2011 Wadsworth Cengage Learning.

30. McQuail, D. McQuail's mass communication theory (6th edition) Thousand Oaks, 2010: SAGE publications Inc.

31. Pwashikai G, Shem W. Appraising the Role and Challenges of Social Media Platforms in Consolidating Democracy in Nigeria. TSU Journal of Communication and Media Studies 2019; 2(1): 188-196.

32. Baran S, Davis D. Mass communication theory: Foundations, ferment, and future. Cengage Learning, 2011.

33. National Open University of Nigeria. Lecture note on mass communication research. 2011 NOUN.

34. Dopoux P, Larson J, Unnikrishnan S, Woods W. Fighting Covid19 in Africa will be different. March 26, 2020-06-17. 